who were coagulopathic on admission versus 3.2\% (range $0 \%-6 \%$ ) in those with normal coagulation studies. Data regarding risk factors and additional outcomes such as transfusion requirements and thrombosis were limited.

Conclusions Acute traumatic coagulopathy is present in around one third of severely injured paediatric patients and is associated with increased mortality, particularly in individuals with isolated brain injuries. The incidence of the condition in the wider paediatric trauma population who do not require admission to intensive care remains largely unknown but may be less common. There was limited data regarding the risk factors and additional outcomes associated with acute traumatic coagulopathy.

\section{G333 RAISE STUDY; A MULTICENTRED STUDY OF INFANTS PRESENTING TO UK EMERGENCY DEPARTMENTS THAT ARE INVESTIGATED FOR SKULLS FRACTURES}

J Le Geyt, L Perera, C Bevan. Paediatric Emergency Department, Royal Alexandra Children's Hospital, Brighton, UK

\subsection{6/archdischild-2018-rcpch.323}

Background Head injury in a young child is a common presentation to emergency departments. Skull fractures in young children often generate concern regarding possible non-accidental injury (NAI). Guidelines produced by the Royal College of Radiology recommend a skeletal survey and CT head in children under 2 years of age, if abusive head injury is suspected. We hypothesise that there are significant variations in practice across the UK with regards to radiological investigations performed, safeguarding referrals, assessments, and follow up.

Methods All hospitals within the PERUKI network were invited to submit data. The study population were children under 2 years who presented to the emergency department and underwent radiological investigation for a suspected skull fracture. Retrospective data was collected for presentations between January 2012 to December 2014 inclusive. Data was collected on the purported mechanisms for the injury, clinical findings, the investigative processes undertaken and subsequent follow-up.

Preliminary results 20 UK emergency departments submitted data. Data was collected for 1583 infants who underwent radiological imaging for a suspected skull fracture. 478 of these $(30 \%)$ had a confirmed skull fracture. $107(7 \%)$ had a likely or definite cause of NAI. Data analysis is ongoing; by February 2018 we will have results of variations in practice across the UK, demographics on event information, symptoms, signs, investigation results of children investigated for skull fractures, and statistical differences in the subgroups of 'no fractures found', 'fractures', and 'fractures likely caused by NAI'.

Conclusion This study will create an extensive database of children less than 2 years old presenting to emergency departments that were investigated for skull fractures. The study aims to produce evidence to inform guidance, enhance clinical decision making in determining the likelihood of skull fractures being found, and NAI as the underlying cause for the skull fracture.

\section{G334}

TAKING THE 'OUCH!' OUT OF EMERGENCY: USING ILLUSTRATIVE AND DIGITAL ARTS TO GUIDE, REASSURE AND ROLE MODEL BEHAVIOURS AT THE CHILDREN'S EMERGENCY DEPARTMENT, EVELINA LONDON CHILDREN'S HOSPITAL

1J Criddle, ${ }^{1} \mathrm{D}$ Hall, ${ }^{2} \mathrm{M}$ Jones, ${ }^{1} \mathrm{R}$ Mitchell. 'Children's Emergency Department, Evelina Children's Hospital, London, UK; ${ }^{2}$ Art in Site, London, UK

\subsection{6/archdischild-2018-rcpch.324}

Background Visiting the Emergency Department (ED) can be an emotive and stressful time for children and their families. A rebuild of The Childrens' Emergency Floor at Evelina London saw the space transformed to create an environment to help with the delivery of healthcare. Breaking away from traditional fantasy graphics, a new art-scheme aims to bring reassurance and stimulation to famililes and children, rolemodelling behaviours and acceptance.

Clinicians worked alongside 'Art In Site', using interactive storytelling to demystify the service. After conducting an environmental psychological study, the design team observed the workings of the department and held workshops with staff, psychologists, patients and families, forging strategic and design prototypes. The project was funded by Guy's and St Thomas's Charity and the art-scheme was installed in late 2016.

Outcomes The project incorporates the following features:

- 'Information Slices': strategically placed text, informing patients at points of need, in simple, jargon-free language.

- A 'gang' of illustrated characters feature in an interactive app, helping demystify the Emergency process through:

- Interactive animations explaining common procedures

- Stories depicting common causes of visits to ED

- Interactive X-ray visualisations of broken bones (and how they'll be fixed)

- Advice to teens on healthy-living, sexual and mental health

- Parental advice about accident prevention and managing illness at home

- Characters integrate with the environment, 'popping out' from doorways, across walls, creeping onto ceilings, and appearing on stickers given to children. They function as information-givers throughout the patient journey.

- 'Bodypaint': a digital interactive installation projected onto a waiting room wall. Dynamic colours and shapes move in response to body movements.

A detailed evaluation is underway but the new scheme has been transformative. The waiting room is calmer, and children and families have a better understanding of their journey through ED. Stress and anxiety have reduced with a subsequent improvement in efficiency.

Conclusions Characters in apps and digital art can role-model clinical scenarios for children. This increases efficiency by reducing anxiety and improving interactions between clinicians, children and their families. Modelling other scenarios, such as common accidents, has potential to educate children and families and may have longer-term public health benefits. 


\section{G335(P) FEVER AFTER MENINGOCOCCAL B IMMUNISATION: A CASE SERIES}

${ }^{1} \mathrm{G}$ Campbell, ${ }^{2} \mathrm{R}$ Bland, 'S Hendry. 'Emergency Department, Royal Hospital for Children, Glasgow, UK; ${ }^{2}$ Paediatric Department, Royal Hospital for Children, Glasgow, UK

10.1136/archdischild-2018-repch.325

Objective To document the clinical features and management of infants presenting with fever after their first meningococcal $B$ vaccination, and develop guidance for clinicians.

Design A prospective case series over a 12 month period.

Setting The Royal Hospital for Children Glasgow, a tertiary paediatric hospital.

Patients Infants $\leq 3$ months of age who had received their first set of immunisations (including Bexsero) within the preceding 72 hours and reported fever.

Results Ninety two infants met the inclusion criteria, accounting for $0.78 \%$ of the local vaccinated population. The most commonly described features were poor feeding, sleepiness and irritability. Sixty six patients $(72 \%)$ were admitted to hospital. Median CRP was $12 \mathrm{mg} / \mathrm{L}$ and median WCC was $16 \times$ $10^{9} /$ L.Fifteen patients $(16 \%)$ had a lumbar puncture and were commenced on antibiotics. There was one confirmed bacterial infection in an infant who had presented with fever starting 54 hours after immunisation. All other microbiology samples were negative. There were no cases of missed serious bacterial infection (SBI) in those patients observed or discharged.

Conclusion Post-immunisation fever is a common presenting problem to the paediatric emergency department. Based on our findings, routine investigations are not warranted if the infant appears well on examination. Where other common side effects are present and there is clinical concern, a period of observation may be a reasonable option. We suggest selective use of investigations, especially inflammatory markers, that are unlikely to discriminate between serious bacterial infection and post-immunisation response. We advocate extra caution in infants presenting with fever more than 48 hours after immunisation.

\section{G336(P) THE IMPACT OF A YOUTH VIOLENCE INTERVENTION PROGRAMME ON REATTENDANCE RATES AND YOUNG PEOPLE'S WELLBEING}

${ }^{1} \mathrm{C}$ Travers, ${ }^{2} \mathrm{G}$ Hann. ${ }^{1}$ Paediatrics and Child Health, University College London, London, UK; ${ }^{2}$ Paediatric Emergency Department, North Middlesex University Hospital, London, UK

\subsection{6/archdischild-2018-rcpch.326}

Introduction Tackling gang violence is a significant challenge. With knife crime and serious youth violence on the rise, the Government has looked towards alternatives to punitive measures. Hospital-based youth violence intervention programmes (YVIP) are one alternative that aim to reduce risk and increase protective factors for gang-related youth violence. Users views of YVIPs have yet to be evaluated in the UK.

Aims We had 2 main aims:

- to compared reattendance rates to $\mathrm{A} \& \mathrm{E}$ of those who engaged with the YVIP and those that refused engagement

- to evaluate the YVIP by examining exit surveys of the young people who had completed the programme

Methods The reattendance rates were analysed for those attending for gang violence who either fully engaged, partially engaged or refused to engage with the programme. The exit survey responses of those patients who had fully engaged were evaluated. The exit survey contained statements that the completed service users responded to based on how strongly they agreed/disagreed with statements. This allowed self-assessment about whether the YVIP had any impact on their lifestyle.

Results Since its inception in October 2014, the YVIP had received 465 referrals. Only 18\% (85 patients) engaged with the service. At the time of study only 15 services users fully engaged and completed the programme. Those patients who had fully engaged had lower reattendance rates $(6.7 \%)$ than those patients who engaged and dropped out (19\%) or those who had refused to engage (26.7\%).

Every completed service user felt that the YVIP had provided helpful support. $33.3 \%(5 / 15)$ strongly agreed that they were much happier since joining the programme. $33.3 \%(5 / 15)$ agreed that they were happier and $33.3 \%(5 / 15)$ were neutral. $73.3 \%(5 / 15)$ felt they were less likely to reattend A and E due to youth violence, whilst $26.7 \%$ (4/15) were neutral. $100 \%(15 / 15)$ strongly agreed that it is a good idea to have a youth support service in the hospital.

Conclusions Although it is hard to engage young people who have been involved in gang violence, there is evidence of the usefulness of YVIPs on both reattendance rates and the well being of those who engage.

\section{G337(P) GENDER, ETHNICITY AND SOCIAL DISADVANTAGE PATTERNS IN ED ATTENDANCE - NOT SUCH A SIMPLE STORY}

${ }^{1} \mathrm{R}$ Choudhury, ${ }^{2} \mathrm{~L}$ Ahmed, ${ }^{2,3} \mathrm{G}$ Oligbu, ${ }^{1,2} \mathrm{M}$ Blair. ${ }^{1}$ Faculty of Medicine, Imperial College, London, UK; ${ }^{2}$ River Island Academic Centre for Paediatrics and Child Health, Northwick Park Hospital, London, UK; ${ }^{3}$ Paediatric Infectious Disease Research Group, St George's University of London, UK

\subsection{6/archdischild-2018-rcpch.327}

Background There are well established gender, ethnicity and socio-economic differences in the incidence and prevalence of epilepsy, autism and allergy sensitisation. ${ }^{1,2,3,4}$ Less is known about these differences within an ED setting.

Simons et al. noted a gender disparity with more boys presenting to ED with sickness, head injury and falls than girls, ${ }^{5}$ but this was not statistically significant.

Aim To establish the role of gender, ethnicity, and social deprivation as factors associated with presentation to ED in children under 5 .

Methods Study design: A retrospective study was conducted on a routine operational data set of basic demographic data collected from a large district general hospital.

Sample: Paediatric ED data 01/04/2015-31/03/2016 for children below 5 years. Levels of deprivation: 2015 Index of Multiple Deprivation. ${ }^{6}$ Office for National Statistics (ONS) mid-year data used for denominator.

Analysis: Descriptive analysis. Rate ratios were calculated for each age. Deciles were obtained for each postcode using 2015 Index of Multiple Deprivation data.

Results Of the 19267 under 16 year-olds paediatric attendances, $10925(56.7 \%)$ were less than 5 years of age. Of these, 6227 (57\%) were male; M:F ratio in ED 1.33 cf. 1.05 local population. The proportion of the population attending ED decreased with age. Presentation rate was consistently higher in males than in females, but the gender gap decreased with age. 